\section{A Case of Tylosis}

Hyperkeratotic plaques on the palms and soles of congenital and familial origin have been variously described as tylosis, ichthyosis palmaris et plantaris, and keratoma palmare et plantaris hereditarium (Unna, 1883, Besnier, 1889).

\section{CASE REPort}

A female child, aged 5 years, was brought to the hospital for treatment of the horny growths on her toes, heels, finger-nails, and palms. At birth the nails were more or less affected. These protuberances had been scraped now and then without the patient feeling any pain; they invariably recurred. When she was 8 months old, a similar horny growth appeared on the right big toe. Gradually it grew larger, and the heels were affected next. One of the growths was removed, and microscopical examination revealed a simple hyperkeratosis. There were several growths on both soles, but the arch of each foot was unaffected. The accompanying photograph gives a fair picture of the condition.

Family History.-Her mother's first pregnancy ended in abortion. There is a sister 3 years old and a brother 8 months old. Both are quite healthy without any cutaneous manifestations like those in the patient. There is no history of the parents or of other members of the family having suffered from warty growths of this kind.

There is no history of arsenic medication. The child is normally developed, though the scalp hair is rather scanty and the lower central incisors have erupted prematurely and are irregularly set.

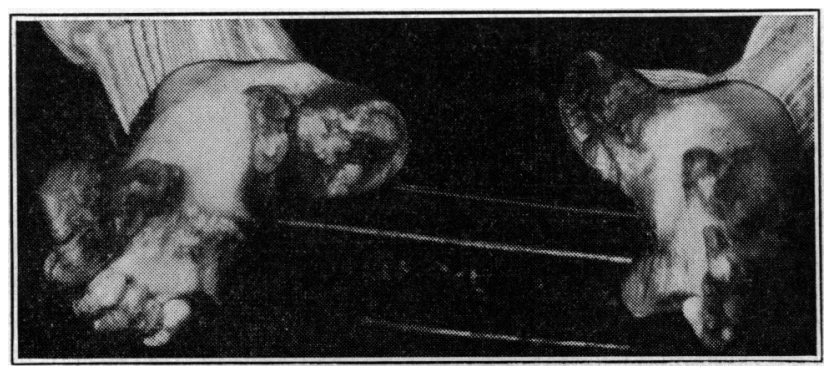

Treatment.-Since the Wassermann reaction was found positive, a full course of bismuth and arsenic was given without any improvement in the warty condition. Subsequently the W.R. became persistently negative. To improve the general health the child was put on a well-balanced diet, supplemented with iron, calcium, and vitamins.

The growths were removed by surgical dissection as completely as possible, and a course of deep $x$-ray treatment was given; recurrence followed. As a palliative measure scraping of the growth was undertaken after softening the part with $10 \%$ potassium hydroxide and applying salicylic acid ointment of strengths varying up to $20 \%$.

\section{Discussion}

This case falls into the age group mentioned by Roxburgh (1947). The symmetrical character of the lesions, absence of inflammatory changes, and the history of its existence from birth are consistent with the findings in the case recorded by Vilvandre (1918). There is no doubt that this is a case of tylosis in its aberrant form. So far as I know no similar case has previously been reported in India.

I am indebted to Dr. T. N. Banerjee for help with the diagnosis and treatment of the case. My thanks are also due to Dr. D. P. Misra, Dr. A. K. Dutta, and Captain J. N. Sinha.

M. A. HaI, M.D.(Patna), M.R.C.P.Ed., Lecturer in Medicine and Physician, P.W. Medical College and Hospital, Patna (Bihar).

\section{REFERENCES}

Besnier, E. (1889). “ Keratodermia Symmetrica Erythemato." International Atlas of Rare Skin Diseases, plate V. Hamburg and Leipzig.

Roxburgh, Ä. C. (1947). Common Skin Diseases, p. 51. London.

Unna, P. G. (1883). Vrtljschr. f. Dermat., 10, 231.

Vilvandre, G. (1918). Brit. J. Derm., 30, 202.

\section{A Case of Paget's Disease Involving the Maxillae}

The following unusual case is interesting enough to be placed on record.

\section{CASE REPORT}

A married woman aged 76 was admitted to hospital after a fall and was unable to move her right arm. Thirty years previously she had had her teeth extracted, and soon after the extraction her face had begun to swell. She had been wearing artificial teeth until ten years ago.

On examination there was a haematoma around a laceration of the scalp. Movement of the right shoulder was painful and limited. She was deaf and almost blind, and had a deep, male type of voice. Her upper jaw was prominent and irregular (Fig. 1). There was overgrowth in size and contour of the alveolar ridges. Her blood pressure was $200 / 100$. A systolic murmur was heard all over the chest. A radiograph of the skull (Fig. 2) revealed" typical " cotton-wool" appear ance. The maxillae were involved, but not the mandible. Both femora and pelvis showed radiological changes of Paget's disease.

The patient was transferred to St. Francis Hospital, and she died there in July, 1949.

\section{COMMENT}

Paget's disease occurs in two forms : (1) localized, in which the clinical changes are limited to one bone - for example, the tibiaand (2) generalized, in which more than one bone is involved.

Da Costa (1921)

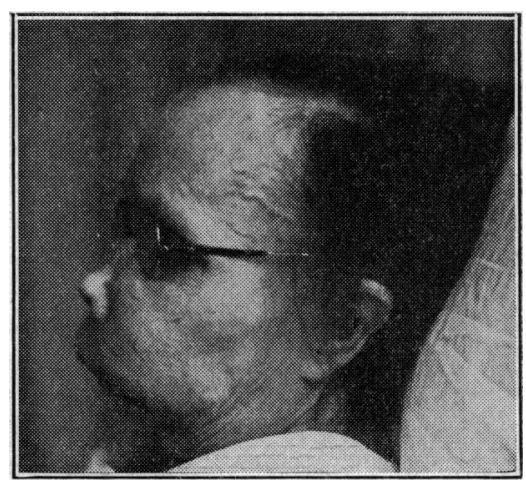

FIg. 1.-Side view showing the prominent upper jaw, en!arged veins, and normal lower jaw.

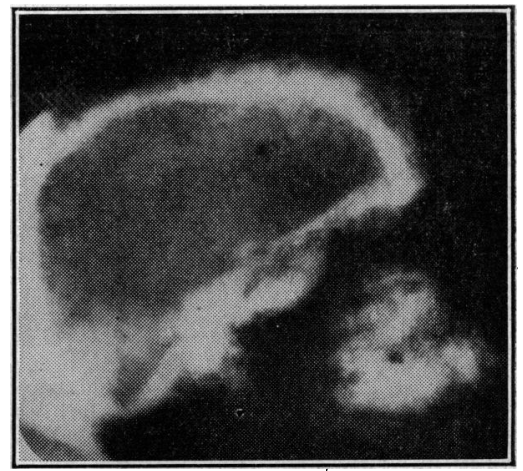

FIG. 2.-Radiograph of sku!l shuw.is? typical " cotton-wool" appearance of Paget's disease involving the maxillae. The mandible is not involved. has stated that the face is seldom affected below the level of the supraorbital margins. The above case shows that the maxillae are also involved: An interesting feature of this case is that the mandible appears quite normal on the radiograph (Fig. 2). Paget's disease involving the facial bones has been extensively reviewed by Novak and Burket (1944).

I wish to thank Dr. O. W. Roberts for permission to publish this case.

\section{B. S. S. Acharya, M.B., F.R.C.S., Dulwich Hospital.}

\section{REFERENCES}

Da Costa, J. C. (1921). Surg. Clin. N. Amer., 1, 47

Novak, A., and Burket, L. W. (1944). Amer. J. Orthodont., 30, 544. 